\title{
Movement of a railway car rolling down a classification hump with a tailwind
}

\author{
Khabibulla Turanov ${ }^{1, *}$, and Andrey Gordienko ${ }^{1}$ \\ ${ }^{1}$ Ural State University of Railway Transport, 620034 Yekaterinburg, Russia
}

\begin{abstract}
The purpose of this paper is to calculate kinematic parameters of a railway car moving with a tailwind for designing a classification hump. The calculation of kinematic parameters is based on the d'Alembert principle, and the physical speed and distance formula for uniformly accelerated or uniformly decelerated motions of a body. By determining a difference between two components - gravitational force of a car and the resistance force of all kinds (frictional resistance, air and wind resistance, resistance from switches and curves, snow and frost resistance), which take place at different sections of a hump profile, the authors calculated the car acceleration at various types of car resistance, as well as time and speed of its movement. Acceleration, time and speed were plotted as a function of the length of a hump profile section. The research results suggest that permissible impact velocities of cars can be achieved by changing profiles of projected hump sections or by using additional hump retarders.
\end{abstract}

\section{Introduction}

A review of studies dedicated to dynamics of cars rolling down humps [1-7] and the applicable design guidelines for classification facilities [8] suggest that there is no method for determining kinematic parameters of a car moving along the entire length of hump profiles, including sections with retarder positions (RP). For example, studies [3-8] focus on designing a hump profile by determining the hump height from its apex to the end of the first retarder position (RP1), then from the beginning of RP1 to the end of the second retarder position (RP2) and, finally, from the beginning of RP2 to the end of the yard retarder position (RP3). Results of the calculation are considered to be valid if a car moving from the hump apex leaves RP3 and reaches the calculation point located $50 \mathrm{~m}$ away from RP3.

Studies [1-8] use Galileo's formula that determines the speed of freely falling bodies taking into account the inertia of rotating masses $v=\sqrt{2 \mathrm{~g}^{\prime} h}$ (see the minuend in formula (8), and formula (9) in [8]). In [1], Galileo's formula is combined with empirical formulas that take into account the resistance arising from rolling wheels along the rail and/or the running resistance (see formula (1) in [1]), as well as resistances that arise when a car passes curves of railway sections (see formula (2) in [1]) and switches (see formula (3) in $[1])$.

\footnotetext{
*Corresponding author: khturanov@yandex.ru
} 
In [1], the total energy of the car is determined as a sum of kinetic energy $\boldsymbol{E}_{\mathbf{0}}$ and potential energy $\boldsymbol{E}_{\mathrm{p}}, \mathrm{kJ}: \boldsymbol{E}_{\mathbf{0}}+\boldsymbol{E}_{\mathrm{p}}$, where $\boldsymbol{E}_{\mathbf{0}}=\boldsymbol{M}\left(\boldsymbol{v}_{\mathbf{0}}\right)^{2} \rho / 2$ (where $\boldsymbol{M}$ is the car weight, $t ; \boldsymbol{v}_{\mathbf{0}}$ is the initial speed, $\mathrm{m} / \mathrm{s} ; \rho$ is the wheel rotation correction factor) and $\boldsymbol{E}_{\mathbf{p}}=\mathrm{g} \boldsymbol{M} \boldsymbol{h}_{\text {hump }}$ (where $\boldsymbol{h}_{\text {hump }}$ is the required hump height, $\mathrm{m}$ ).

It is commonly known [9] that the total energy remains constant: this state is called the law of conservation of energy. In [1], in contrast to the law of conservation of energy, the total energy $\boldsymbol{E}_{\mathbf{0}}+\boldsymbol{E}_{\mathrm{p}}$ is equated to the work of a projected gravitational force component $(\boldsymbol{G} \sin \psi)$ of the moving car, i.e. the law of conservation of energy is violated (see page 293 in [9]).

The total energy in [1] is assumed to be equal to the sum of works done by all resistance forces, including those arising when the car moves between the hump apex and the reference point (100 $\mathrm{m}$ beyond the tangent point) $\boldsymbol{A}_{\mathrm{r}}$, passes a curved track section $\boldsymbol{A}_{\mathrm{c}}$ and collides with switches $\boldsymbol{A}_{\mathrm{s}}$. Otherwise, $\boldsymbol{E}_{\mathbf{0}}+\boldsymbol{E}_{\mathrm{p}}=\boldsymbol{A}_{\mathrm{r}}+\boldsymbol{A}_{\mathrm{c}}+\boldsymbol{A}_{\mathrm{s}}$ (see the mathematical expression (6) in [1]). This contradicts the work-energy theorem that defines a change in kinetic energy for a constrained material point in a finite form: $\Delta \boldsymbol{E}=\left|\boldsymbol{A}_{\mathbf{r}, \mathbf{c}, \mathbf{s}}\right|$, where the work of the resistance forces $\left|\boldsymbol{A}_{\mathbf{r}, \mathbf{c}, \mathbf{s}}\right|=-\boldsymbol{A}_{\mathbf{r}, \mathbf{c}, \mathbf{s}}$ must have a negative sign [9]. Any effort to determine the required hump height $\boldsymbol{h}_{\text {hump }}$ using relation (6) in [1] is quasi-scientific.

Studies [3-8] use the Galileo's formula $\left(v=\sqrt{2 \mathrm{~g}^{\prime} h}\right)$ in combination with resistances of all kinds, i.e. with the main (net train) resistance (see (4.9) in [8]), air and wind resistances (see formula (4.10) in [8]), snow and frost resistances (see formula (4.11) in [8]), resistances arising when the car passes switches (see (4.13) in [8]) and curved track sections (see formula (4.14) in [8]).

The application of the Galileo's formula is invalid $\left(v=\sqrt{2 \mathrm{~g}^{\prime} h}\right)$ since it is applicable only to the ideal constraint, while resistances of all kinds are classified as non-ideal constraints [9]. These physically incompatible concepts seem to be widely used in the literature, for example, in the same formula for estimating hump heights and rolling-down speed of a car, both at high-speed sections and retarder positions of the hump. This approach is fundamentally wrong and unacceptable $[10,11]$. As noted in $[10,11]$, the rolling-down speed of a car along the entire hump profile length, including sections with retarder positions [1-8], has not yet been determined.

Taking this into account, studies $[10,11]$ describe in detail a simplified method for constructing a mathematical model of the car movement along the hump profile, while [11, 12] provide specific calculations as examples. A reasonable approach to determining the longitudinal profile of the inclined hump part has remained a problem over many years. Authors of available studies [3-8] tend to normalize the rolling-down speed for each section of the inclined part (Table 4.7 in [8]) and then calculate the average time of movement, without taking into account the nature of movement and the real meaning of related physical processes.

The purpose of this study is to illustrate how the time and speed of the car movement along the entire length of the hump profile can be calculated using a simplified procedure. Using a known value of the car acceleration, it is necessary to find $\boldsymbol{t}_{\boldsymbol{k}}$, during which the car moves at a specified initial speed $\boldsymbol{v}_{\mathbf{0}}$ to the end of the tested hump section. Based on a known value of $\boldsymbol{t}_{\boldsymbol{k}}$, the speed $v\left(\boldsymbol{t}_{\boldsymbol{k}}\right)$ of the car leaving any hump section $\boldsymbol{k}$ can be determined.

\section{Research methods}

Previously, the engineering problem of determining the kinematic parameters (acceleration, time and speed) of the car moving along the hump profile was solved using the fundamental law of dynamics for non-ideal constraints (d'Alembert principle), as well as speed and distance formulas of elementary physics. The car speed on segments with retarder positions 
was found subject to the assumption that the hump retarder was used to the fullest extent (i.e. full stop of the car). Based on these findings, a refined method was proposed to calculate kinematic parameters of car movement on sections of longitudinal hump profiles $[10,11]$.

The proposed method makes it possible to determine efficient shunting conditions and efficiently combine powers of retarder positions. This ensures that permissible car impact velocities established for classification yards by the applicable operating rules will be maintained. Based on the developed refined method, the authors developed a program for calculating kinematic parameters of car movement on sections of longitudinal hump profiles [12]. The program is designed to calculate car accelerations, speeds and time on sections of longitudinal hump profiles. Operating parameters of humps are used as input data for the program.

The program is adapted to real current conditions under the assumption that any geometric parameters (grade $\boldsymbol{i}_{\boldsymbol{k}}$, section length $\boldsymbol{l}_{\boldsymbol{k}}$ ) of any hump section $\boldsymbol{k}$ are easily adaptable, e.g., to weather conditions.

\section{Input data and results}

Using the calculation program mentioned above [12], we studied the influence of the hump profile grade and placement of the third retarder position on a curved track on kinematic parameters of a car rolling down the hump. The calculated data are presented below.

The following shunting conditions were considered: (1) movement of a very bad runner ${ }^{1}$ with a tailwind; (2) powers of retarder positions (RP1, RP2 and RP3) are used to the fullest extent; where RP1 and RP2 include length wheelbase (WhB), breaking zone (SB) and break release zone (RS), whereas RP3 includes only breaking zone (SB) and break release zone (RS); (3) the third retarder position (RP3) is located on straight or curved track sections.

First we consider the case with a concave hump profile (e.g., $35 \%$ on the first highspeed section (HS1), $18 \%$ on the second high-speed section (HS2), $13 \%$ on RP1, $10 \%$ o on the intermediate section (IS), $10 \%$ on RP2, $1.2 \%$ on the switch zone (Sw), $1.0 \%$ on the first classification track (CT1), $0.6 \%$ on the second classification track (CT2), and the third retarder position located on a straight track section.

The calculated data are summarized in Table 1 in a form convenient for constructing the characteristic curves for acceleration $\boldsymbol{a}_{k}$, time $\boldsymbol{t}_{\boldsymbol{k}}$ and speed $\boldsymbol{v}_{\mathrm{K}}$ of a car moving on each section $\boldsymbol{l}_{\boldsymbol{k}}$ of the inclined hump part, i.e. for $\boldsymbol{a}_{\boldsymbol{k}}=\boldsymbol{f}\left(\boldsymbol{l}_{\boldsymbol{k}}\right), \boldsymbol{t}_{\boldsymbol{k}}=\boldsymbol{f}\left(\boldsymbol{l}_{\boldsymbol{k}}\right)$ and $\boldsymbol{v}_{\boldsymbol{k}}=\boldsymbol{f}\left(\boldsymbol{l}_{\boldsymbol{k}}\right)$ ).

Table 1. Calculated kinematic parameters of a car rolling down the hump, with the third retarder position on a straight track section.

\begin{tabular}{|c|c|c|c|c|c|c|c|c|}
\hline \multirow{4}{*}{$\begin{array}{c}\text { Sections } \\
\text { of the } \\
\text { inclined } \\
\text { hump } \\
\text { part }\end{array}$} & \multirow{3}{*}{$\begin{array}{l}\text { Elements of } \\
\text { sections } \\
\text { of the } \\
\text { inclined } \\
\text { hump part }\end{array}$} & $l_{k}$ & $i_{k}$ & $\boldsymbol{h}_{k}$ & $a_{k}$ & $t_{k}$ & \multicolumn{2}{|c|}{$v_{k}$} \\
\hline & & \multicolumn{2}{|c|}{$\begin{array}{l}\text { Input } \\
\text { values }\end{array}$} & \multicolumn{5}{|c|}{ Calculated values } \\
\hline & & $m$ & $\%$ & $m$ & $m / s^{2}$ & $s$ & $m / s$ & $\mathrm{~km} / \mathrm{h}$ \\
\hline & HA & - & & - & - & - & 1.7 & 6.12 \\
\hline HS1 & HS1 & 39.924 & 35 & 1.396 & 0.372 & 10.779 & 5.708 & 20.55 \\
\hline \multirow{2}{*}{ HS2 } & Before Sw & 54.935 & \multirow{2}{*}{18} & 1.666 & 0.205 & 13.294 & 6.224 & 22.41 \\
\hline & After Sw & 73.569 & & 2.001 & 0.20 & 16.156 & 6.795 & 24.46 \\
\hline
\end{tabular}

\footnotetext{
${ }^{1}$ The very bad runner means a car with a calculated gravitational force of $220 \mathrm{kN}$ and main specific resistance of 0.8 .
} 


\begin{tabular}{|c|c|c|c|c|c|c|c|c|}
\hline \multirow{3}{*}{ RP1 } & WhB & 81.87 & \multirow{3}{*}{13} & 2.109 & 0.156 & 17.361 & 6.983 & 26.18 \\
\hline & SB & 95.212 & & 2.125 & -2.037 & 20.761 & 0.057 & 0.205 \\
\hline & $\mathrm{RS}$ & 102.57 & & 2.239 & 0.156 & 30.98 & 1.652 & 5.95 \\
\hline \multirow{2}{*}{ IS } & Before $\mathrm{Sw}$ & 122.571 & \multirow[b]{2}{*}{10} & 2.439 & 0.127 & 39.98 & 2.792 & 10.05 \\
\hline & After Sw & 143.842 & & 2.649 & 0.121 & 46.64 & 3.596 & 12.95 \\
\hline \multirow{3}{*}{ RP2 } & WhB & 154.243 & \multirow{3}{*}{10} & 2.753 & 0.127 & 49.398 & 3.945 & 14.2 \\
\hline & SB & 158.15 & & 2.791 & -2.067 & 51.298 & 0.019 & 0.067 \\
\hline & $\mathrm{RS}$ & 174.843 & & 2.959 & 0.127 & 67.456 & 2.065 & 7.435 \\
\hline \multirow{4}{*}{$\mathrm{Sw}$} & Before $\mathrm{Sw} 1$ & 190.843 & \multirow{4}{*}{1.2} & 2.978 & 0.04 & 74.692 & 2.357 & 8.49 \\
\hline & Sw1 & 216.533 & & 3.009 & 0.033 & 84.858 & 2.697 & 9.71 \\
\hline & Sw2 & 237.533 & & 3.034 & 0.033 & 92.305 & 2.943 & 10.6 \\
\hline & Sw3 & 261.533 & & 3.063 & 0.033 & 100.115 & 3.2 & 11.53 \\
\hline CT1 & CT1 & 320.713 & 1.0 & 3.122 & 0.038 & 116.926 & 3.837 & 13.81 \\
\hline \multirow[b]{2}{*}{ RP3 } & SB & 326.963 & \multirow{2}{*}{$\begin{array}{c}1.5 \\
\text { straight } \\
\text { section }\end{array}$} & 3.127 & -2.15 & 118.626 & 0.182 & 0.657 \\
\hline & RS & 330.977 & & 3.144 & 0.041 & 137.884 & 0.969 & 3.487 \\
\hline CT2 & CT2 & 385.213 & 0.6 & 3.173 & 0.034 & 170.539 & 2.094 & 7.537 \\
\hline
\end{tabular}

Abbreviations in Table 1: RS is the remaining section with retarder positions. The research results for the third retarder position (RP3) located on the straight section suggest that, when approaching the calculation point (CP), the car has a speed of $\boldsymbol{v}_{\mathrm{eCP}} \approx 2.1 \mathrm{~m} / \mathrm{s}$ (or $\approx 7.5 \mathrm{~km} / \mathrm{h}$ ). It should be noted that at $\boldsymbol{v}_{\mathrm{eCP}} \approx 2.1 \mathrm{~m} / \mathrm{s}$, the average car speed is equal to $\boldsymbol{v}_{\mathrm{eCPm}}$ $\approx 1.53 \mathrm{~m} / \mathrm{s}$, which is less than the permissible average car speed on the second classification track $(\mathrm{CT} 2)$, i.e. $\left[v_{\mathrm{eCP}}\right]=2.0 \mathrm{~m} / \mathrm{s}$.

Thus, the specified shunting conditions will not allow the car to achieve the rated speed when approaching to a group of cars in the hump yard $(5 \mathrm{~km} / \mathrm{h})$ [8]. Using the values in Table 1, variation of the car acceleration over the entire length of the track lk are plotted as a function of tailwind of a small value Frwx, subject to the resistance force of all kinds Fr. (Fig. 1).

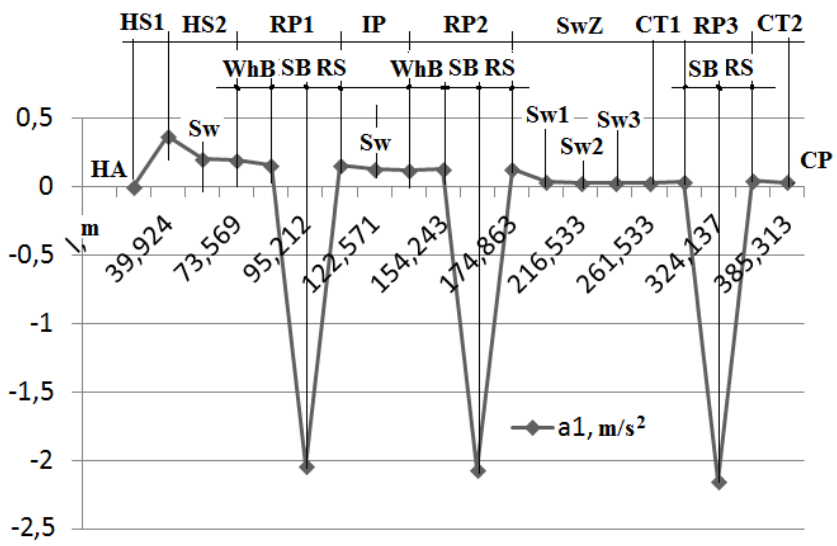

Fig. 1. Variation of acceleration when the car is rolling down the hump, with the third retarder position on a straight track section.

The abbreviations in Figure 1 are similar to those in Table 1. From Figure 1, it is clear that, on sections with retarder positions RP1, RP2 and RP3, the car has uniform deceleration with negative values, i.e. $\boldsymbol{a}_{\mathrm{rp} 1}<0, \boldsymbol{a}_{\mathrm{rp} 2}<0$ and $\boldsymbol{a}_{\mathrm{rp} 3}<0$ (where $\left|\boldsymbol{a}_{\mathrm{rp} 1}\right|=-\boldsymbol{a}_{\mathrm{rp1}}$, $\left|\boldsymbol{a}_{\mathrm{rp2}}\right|=-\boldsymbol{a}_{\mathrm{rp2}}$, and $\left.\left|\boldsymbol{a}_{\mathrm{rp3}}\right|=-\boldsymbol{a}_{\mathrm{rp3}}\right)$.

Les us write the variation of the car acceleration, which is graphically presented above, in mathematical form. Assume that the car is retarded on the first retarder position (RP1), which is used to the fullest extent: 


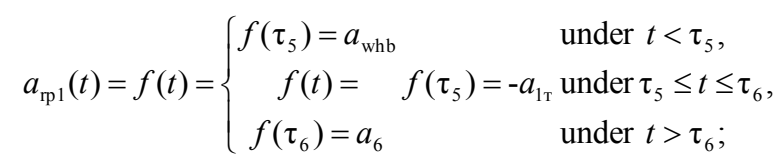

Similar to the characteristic curve $a_{k}=f\left(l_{k}\right)$, characteristic curves $t_{k}=f\left(l_{k}\right)$ (Fig. 2), $v_{k}=$ $\boldsymbol{f}\left(\boldsymbol{l}_{\boldsymbol{k}}\right)$ (Fig. 3) were plotted using the values from Table 1.

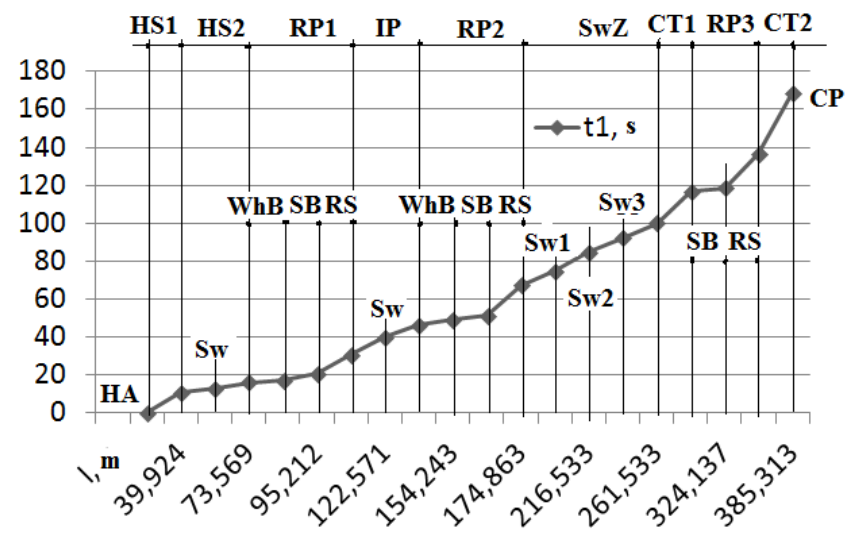

Fig. 2. Variation of the time of car movement on the hump inclined part.

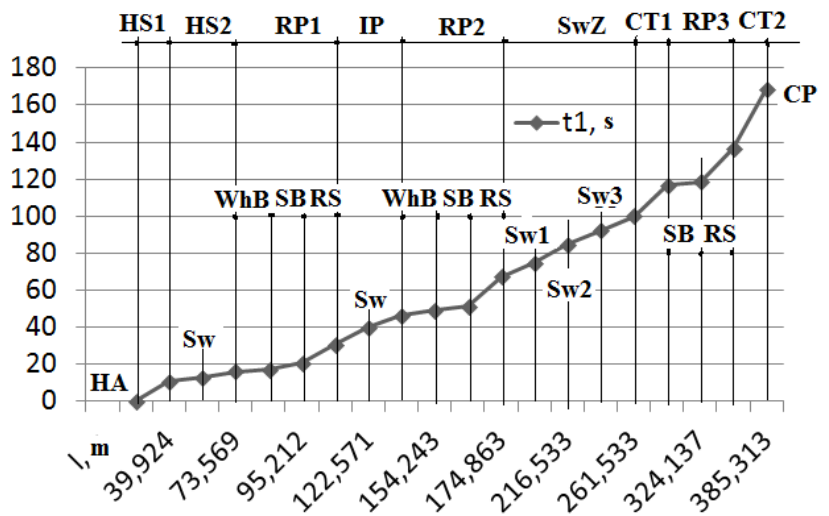

Fig. 3. Variation of the car speed on the hump inclined part.

From Figure 3 it is clear that the car speed falls to almost zero in the retardation zones where linear acceleration values are negative (Fig. 1). This is due to the fact that all retarder positions are used to the fullest extent.

Let us present the calculated kinematic parameters of the car rolling down the hump, with the third retarder position on a curved track section and grade increased to $2 \%$, as shown in Table 2 . 
Table 2. Calculated kinematic parameters of a car rolling down the hump, with the third retarder position on a curved track section.

\begin{tabular}{|c|c|c|c|c|c|c|c|c|}
\hline \multirow{4}{*}{$\begin{array}{l}\text { Sections } \\
\text { of the } \\
\text { inclined } \\
\text { hump } \\
\text { part }\end{array}$} & \multirow{3}{*}{$\begin{array}{l}\text { Elements of } \\
\text { sections } \\
\text { of the } \\
\text { inclined } \\
\text { hump part }\end{array}$} & $l_{k}$ & $i_{k}$ & $\boldsymbol{h}_{k}$ & $a_{k}$ & $\boldsymbol{t}_{k}$ & \multicolumn{2}{|c|}{$v_{k}$} \\
\hline & & \multicolumn{2}{|c|}{$\begin{array}{l}\text { Input } \\
\text { values }\end{array}$} & \multicolumn{5}{|c|}{ Calculated values } \\
\hline & & $m$ & $\%$ & $m$ & $m / s^{2}$ & $s$ & $m / s$ & $\mathrm{~km} / \mathrm{h}$ \\
\hline & HA & - & & - & - & - & 1.7 & 6.12 \\
\hline HS1 & HS1 & 39.924 & 35 & 1.396 & 0.372 & 10.779 & 5.708 & 20.55 \\
\hline \multirow{2}{*}{ HS2 } & Before $\mathrm{Sw}$ & 54.935 & \multirow{2}{*}{18} & 1.666 & 0.205 & 13.294 & 6.224 & 22.41 \\
\hline & After Sw & 73.569 & & 2.001 & 0.20 & 16.156 & 6.795 & 24.46 \\
\hline \multirow{3}{*}{ RP1 } & WhB & 81.87 & \multirow{3}{*}{13} & 2.109 & 0.156 & 17.361 & 6.983 & 26.18 \\
\hline & SB & 95.212 & & 2.125 & -2.037 & 20.761 & 0.057 & 0.205 \\
\hline & RS & 102.57 & & 2.239 & 0.156 & 30.98 & 1.652 & 5.95 \\
\hline \multirow{2}{*}{ IS } & Before Sw & 122.571 & \multirow{2}{*}{10} & 2.439 & 0.127 & 39.98 & 2.792 & 10.05 \\
\hline & After Sw & 143.842 & & 2.649 & 0.121 & 46.64 & 3.596 & 12.95 \\
\hline \multirow{3}{*}{ RP2 } & WhB & 154.243 & \multirow{3}{*}{10} & 2.753 & 0.127 & 49.398 & 3.945 & 14.2 \\
\hline & SB & 158.15 & & 2.791 & -2.067 & 51.298 & 0.019 & 0.067 \\
\hline & $\mathrm{RS}$ & 174.843 & & 2.959 & 0.127 & 67.456 & 2.065 & 7.435 \\
\hline \multirow{4}{*}{ Sw } & Before Sw1 & 190.843 & \multirow{4}{*}{1.2} & 2.978 & 0.04 & 74.692 & 2.357 & 8.49 \\
\hline & Sw1 & 216.533 & & 3.009 & 0.033 & 84.858 & 2.697 & 9.71 \\
\hline & Sw2 & 237.533 & & 3.034 & 0.033 & 92.305 & 2.943 & 10.6 \\
\hline & Sw3 & 261.533 & & 3.063 & 0.033 & 100.115 & 3.2 & 11.53 \\
\hline CT1 & CT1 & 320.713 & 1.0 & 3.122 & 0.038 & 116.926 & 3.837 & 13.81 \\
\hline \multirow[b]{2}{*}{ RP3 } & SB & 324.137 & \multirow{2}{*}{$\begin{array}{c}2.0 \\
\text { curved } \\
\text { section }\end{array}$} & 3.129 & -2.145 & 118.626 & 0.191 & 0.687 \\
\hline & RS & 335.313 & & 3.350 & 0.046 & 136.856 & 1.024 & 3.69 \\
\hline CT2 & CT2 & 385.313 & 0.6 & 3.650 & 0.034 & 168.658 & 2.12 & 7.63 \\
\hline
\end{tabular}

The calculated data presented above for the third retarder position (RP3) located on the curved section suggest that, when approaching the calculation point $(\mathrm{CP})$, the car has a speed of $\mathbf{v}_{\mathrm{eCP}} \approx 2.12 \mathrm{~m} / \mathrm{s}$ ( or $\approx 7.63 \mathrm{~km} / \mathrm{h}$ ). It should be noted that at $\mathbf{v}_{\mathrm{eCP}} \approx 2.12 \mathrm{~m} / \mathrm{s}$, the average car speed is equal to $\mathbf{v}_{\mathrm{eCPm}} \approx 1.57 \mathrm{~m} / \mathrm{s}$, which is less than the permissible average car speed on the second classification track $(\mathrm{CT} 2)$, i.e. $\left[\mathbf{v}_{\mathrm{eCP}}\right]=2.0 \mathrm{~m} / \mathrm{s}$.

By comparing Tables 1 and 2, we can conclude that an increase in the grade of the third retarder position and its location on the curved track section slightly influence the impact velocity of cars in the hump yard $(7.537 \mathrm{~km} / \mathrm{h}$ and $7.63 \mathrm{~km} / \mathrm{h})$.

For the case where the third retarder position is located on the curved track section, the total length of the inclined hump part from the hump apex up to calculation point is equal to $\mathbf{L}_{\text {cr }} \approx 385.31 \mathrm{~m}$ (versus $\mathbf{L}_{\text {straight }} \approx 385.21 \mathrm{~m}$ ). The total time of car movement $\mathbf{t}_{\text {tot.cur }} \approx$ $168.7 \mathrm{~s}$ (versus $\mathbf{t}_{\text {tot.straight }} \approx 170.6 \mathrm{~s}$ ). This is consistent with the data in Table 1 . The characteristic curves $\mathbf{a}_{\mathbf{k}}=\mathbf{f}\left(\mathbf{l}_{\mathbf{k}}\right), \mathbf{t}_{\mathbf{k}}=\mathbf{f}\left(\mathbf{l}_{\mathbf{k}}\right)$ and $\mathbf{v}_{\mathbf{k}}=\mathbf{f}\left(\mathbf{l}_{\mathbf{k}}\right)$, plotted according to the data in Table 2 , are similar to those based on the data from Figures 1-3.

Moreover, the shunting conditions considered above will not allow the car to achieve the rated speed when approaching to a group of cars in the hump yard [8].

Permissible impact velocities under the specified conditions can be achieved either by changing the profile of separate sections in the inclined hump part, or by using additional car retarders. 


\section{Conclusion}

The proposed refined method for calculating kinematic parameters of cars moving along longitudinal profiles of humps and the related calculation program make it possible to determine efficient shunting conditions. Using the calculation program, the authors studied the influence of the profile grade and the location of the third retarder position on kinematic parameters of cars moving along longitudinal profiles of humps, and presented the results of these studies. When the third retarder position is located on both straight and curved track sections, the rated speed of a car approaching a group of cars in the hump yard cannot be achieved. Permissible impact velocities under the specified conditions can be achieved either by changing profiles of separate sections in the inclined hump part, or by using additional car retarders.

Relying on the parameters calculated according to the simplified procedure, including the known distance traveled by the car along the entire length, e.g. the 1RP section of the hump $l_{\mathrm{rp}}$, and the calculated uniform deceleration of the car $a_{0 \text { rp } 1}$, the authors calculated the braking time $t_{\mathrm{rp} 1}$ and the braking distance $l_{\mathrm{rp} 1}$ of the car in the section with retarder positions. Based on a value of $t_{\mathrm{rp} 1}$, the authors determined the car speed in the section with retarder positions at the time when the rail brake was released $v_{\mathrm{rb}}\left(t_{\mathrm{rp} 1}\right)$, i.e. when the car left the retarder positions of this section. The results of these studies can be used to calculate and design classification humps.

\section{References}

1. J. Prokop, Sh. Myojin, Memoirs of the Faculty of Engineering, Okayama University, Vol. 27, 2, 41 - 58 (1993).

2. S. Zarecky, J. Grun, J. Zilka, Transport Problems, Provlemy Transportu, Vol. 3, 4, 87 -95 (2008).

3. V. Bobrovsky, D. Kozschenko, A. Dorosh, E. Demchenko, T. Bolovanovska, A. Kolesnik, Transport Problems, Provlemy Transporty, Vol. 3, Issue I, 147 - 155 (2016).

4. V.M. Rudanovskiy, I.P. Starshov, V.A. Kobzev, Bulletin of Transport Information, 6 (252), 19 - 28 (2016). (in Russian)

5. Yu.O. Pozojskiy, V.A. Kobzev, I.P. Starshov, V.M. Rudanovskiy, Bulletin of Transport Information, 2 (272), 35- 37 (2018). (in Russian)

6. V.N. Obraztsov, Stancii i uzly, ch. II [Stations and nodes, Part II] (Transzheldorizdat, Moscow, 1938). (in Russian)

7. V.I. Apatcev, Yu.I. Efimenko, Zheleznodorozhnye stancii i uzly [Railway stations and nodes] (Moscow, 2014). (in Russian)

8. Pravila i normy proektirovanija sortirovochnyh ustrojstv na zheleznyh dorogah kolei 1 $520 \mathrm{~mm}$ [Rules and design standards for assorting works on railways of gauge 1,520 $\mathrm{mm}$ ] (TEHINFORM, Moscow, 2003). (in Russian)

9. S.P. Timoshenko, D. Yung, Inzhenernaja mehanika [Engineering mechanics] (Mashgiz, Moscow, 1960). (in Russian)

10. Kh.T. Turanov, A.A. Gordienko, Mir transporta [World of Transport and Transportation Journal], 14, 4 (65), 86-91 (2016). (in Russian)

11. Kh.T. Turanov, A.A. Gordienko, Certificate of official registration of the computer program, No. RU 2017614017 of 05.04.17 (2017). (in Russian) 